\title{
SEGUNDO REPERTÓRIO BIBLIOGRÁFICO DOS ESTUDOS EM LÍNGUA PORTUGUESA DEDICADOS A PLOTINO E AO NEOPLATONISMO DA ANTIGUIDADE TARDIA
}

\author{
Loraine Oliveira * \\ Luciana Gabriela Soares Santoprete** \\ Mayã Gonçalves Fernandes***
}

Recebido em: 13/12/2019

Aprovado em: 07/01/2020

RESUMO: Este artigo constitui a segunda lista completa das referências bibliográficas lusófonas sobre as filosofias neoplatônicas da Antiguidade tardia; dá continuidade ao primeiro repertório publicado em 2010 e cataloga os trabalhos (livros, artigos, teses e dissertações) publicados desde então, sendo acompanhado de quatro índices: um de autores contemporâneos, um de tradutores, um de autores antigos e um de assuntos.

PALAVRAS-CHAVE: filosofia; neoplatonismo; bibliografia; Antiguidade tardia.

SECOND BIBLIOGRAPHIC REPERTOIRE OF STUDIES IN PORTUGUESE LANGUAGE DEDICATED TO PLOTINUS AND NEOPLATONISM OF LATE ANTIQUITY

\begin{abstract}
This article is the second complete list of Lusophone bibliographical references on the Neoplatonic philosophies of Late Antiquity. This article continues the first repertoire published in 2010 and catalogues the works (books, articles, thesis and dissertations) published since then, being accompanied by four indexes: an index of contemporary authors, an index of translators, an index of ancient authors and an index of subjects.
\end{abstract}

KEYWORDS: Philosophy; neoplatonism; bibliography; late Antiquity.
*Professora Associada, Departamento de Filosofia, Universidade Federal de Pernambuco.

loraineoliveira13@gmail.com

**Chargée de recherche au CNRS, Laboratoire d'Études sur les Monothéismes (LEM - UMR 8584) com apoio da Universität Wien (FWF - Der Wissenschaftsfonds). soaressantoprete@gmail.com ***Doutoranda em Artes Visuais, Universidade de Brasília. Bolsista da Coordenação de Aperfeiçoamento de Pessoal de Nível Superior, CAPES. 


\section{Apresentação}

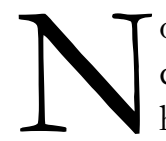

o último decênio observa-se que os estudos sobre o neoplatonismo antigo cresceram consideravelmente no Brasil e em Portugal. De 2010 até os dias de hoje, encontramos 157 obras dedicadas a autores neoplatônicos incluindo livros, capítulos de livros, artigos de periódicos, teses e dissertações. Entre os anos de 1964 e 2010, foram localizadas 151 obras. Com isso, totalizam-se 303 publicações, sendo que o último decênio representa pouco mais que a metade do total. Com efeito, em 2010, foi elaborado o Primeiro repertório bibliográfico dos estudos em língua portuguesa dedicados ao neoplatonismo da Antiguidade Tardia, publicado em 3 artigos, ${ }^{1}$ na versão eletrônica da Revista Archai n. 5. O terceiro desses três artigos, sem os resumos, foi em seguida publicado no blog de pesquisa Les Platonismes de l'Antiquité Tardive ${ }^{2}$ visando, a longo termo, reunir e atualizar todas as referências e proporcionar um acesso mais dinâmico ao trabalhos lusófonos. Naqueles 46 anos, de 1964 a 2010, a maioria dos estudos versava sobre Plotino, seguido quantitativamente por Boécio, Porfírio, Proclo, Jâmblico, Damáscio e Sinésio de Cirene. Vale ressaltar que os temas "estética" e "mística" foram visivelmente os mais estudados.

Decorridos nove anos desde a publicação do Primeiro repertório bibliográfico, eis que foi produzido o Segundo repertório. Assim como o primeiro, este segundo é composto por referências bibliográficas de livros, capítulos de livros, artigos de periódicos, teses e dissertações, nas quais os filósofos neoplatônicos são nomeados explicitamente no título. Não foi possível aqui catalogar, vista a complexidade que um tal trabalho implicaria, as obras que abordassem também, mas não somente, os autores neoplatônicos, caso isso não tenha sido indicado no título do trabalho, como exemplo, o artigo de Luciana Gabriela Soares Santoprete, "A questão da localização dos inteligíveis nos filósofos pagãos dos primeiros séculos da era cristã", publicado em Anais de Filosofia Clássica, v. 7, n. 13, 2013, p. 1-22, cuja parte final é dedicada a Plotino. Também vale notar que, dada a dificuldade de acesso às Atas de congresso, os resumos de trabalhos apresentados não foram incluídos no Primeiro repertório e, nesse segundo, foram mencionados somente aqueles encontrados através dos instrumentos de busca eletrônica atualmente disponíveis. A propósito, cabe observar que neste Segundo repertório são mencionados alguns títulos referentes aos anos de 2008, 2009 e 2010 que, todavia, haviam escapado ao Primeiro repertório.

1 (1) Primeiro repertório bibliográfico dos estudos em língua portuguesa dedicados ao neoplatonismo da Antiguidade Tardia. Parte I: Histórico da pesquisa. Luciana Gabriela Soares Santoprete. https://periodicos.unb.br/ index.php/archai/article/view/2944/2644. (2) Anexo à Parte I do Primeiro repertório bibliográfico dos estudos em língua portuguesa dedicados ao neoplatonismo da Antiguidade Tardia. Luciana Gabriela Soares Santoprete, Loraine Oliveira e Emmannuela Freitas de Caldas. https://periodicos.unb.br/index.php/archai/ article/view/2945. (3) Primeiro repertório bibliográfico dos estudos em lingua portuguesa dedicados ao neoplatonismo da Antiguidade Tardia. Parte II: Elenco de autores e titulos. Luciana Gabriela Soares Santoprete, Loraine Oliveira, Emmannuela Freitas de Caldas. https://periodicos.unb.br/index.php/archai/article/ view/2946/2646.

${ }^{2}$ Trata-se do blog de pesquisa que acompanha a base de dados dirigida por Luciana Gabriela Soares Santoprete (ver https://platonismes.huma-num.fr/). 
Como podemos constatar nos gráficos apresentados a seguir, o campo de autores e tipo de trabalho vem se alargando. Contudo, Plotino continua sendo o autor mais estudado, seguido de Proclo, Boécio e Jâmblico. Em menor quantidade, encontramos Porfírio, Juliano e Hipácia: ${ }^{3}$

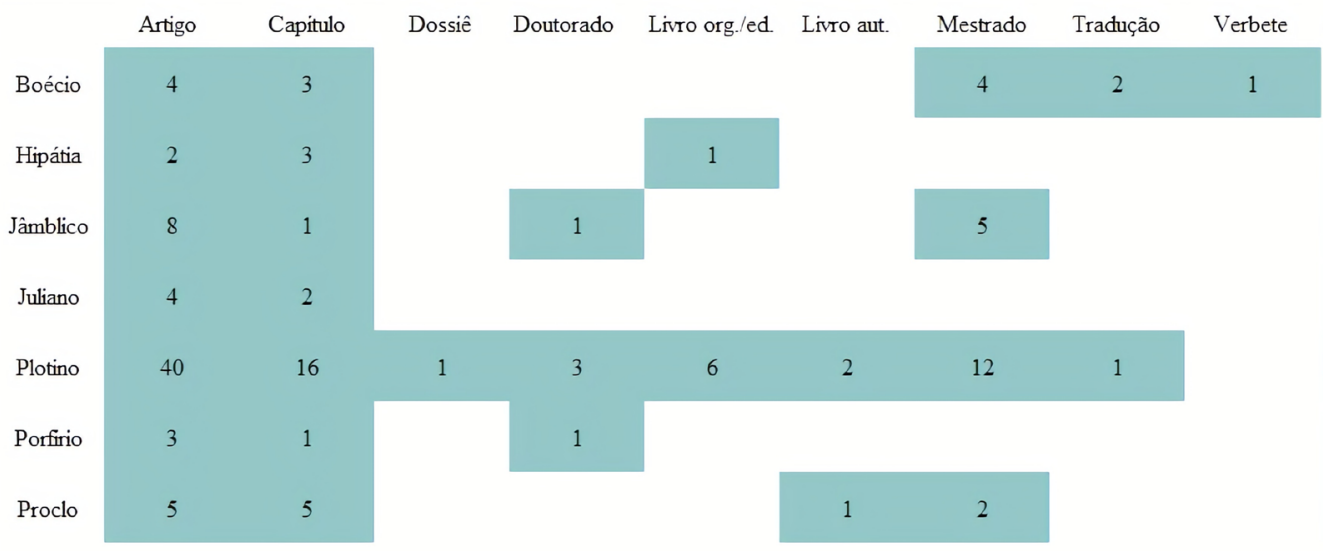

A estes gráficos, que ilustram o que foi dito, pode-se acrescentar:

Dentre os livros, nota-se que, tal como antes, encontram-se obras coletivas sobre Neoplatonismo, obras individuais sobre temas em particular e, como teremos oportunidade de comentar à frente, algumas traduções de livros de autores hodiernos, relevantes para os estudos em escopo.

Quanto às teses e dissertações, observa-se um crescimento significativo. Do ponto de vista do conteúdo, são constituídas por estudos de questões específicas em um texto ou cotejando diversos textos de um mesmo autor.

Em conformidade com o interesse cada vez mais vivo pelo estudo das mulheres filósofas, surgiram neste período 5 trabalhos sobre Hipácia: 2 capítulos de livro, um em 2015 (n. 121), outro em 2016 (n. 128), um artigo em 2016 (n. 132) e, por fim, em 2019, 2 capítulos análogos a verbetes de dicionário (n. 157 e 158), caracterizados por constituírem uma breve descrição da vida e da morte de Hipácia. Addenda ao primeiro repertório: em 2009, foi publicada em Lisboa a tradução do livro de Maria Dzielska, Hipátia de Alexandria (n. 4), e em 2010 foi publicado no Brasil um livro de cordel chamado Hipátia: a guardiã da ciência, heroína e mártir (n. 26).

Germinal interesse tem despertado o Diádoco de Atenas: 15 ocorrências do nome Proclo revelam 5 artigos (n. 7, 10, 34, 88 e 109), 1 dissertação de mestrado (n. 143) e 5 capítulos de livros (n. 123, 138, 139, 144 e 147), sendo que os quatro últimos integram o

\footnotetext{
${ }^{3}$ Nas ocorrências repertoriadas, encontram-se três grafias distintas para o mesmo nome: Hipácia, Hipátia, Hypacia. A forma aportuguesada correta é "Hipácia". Os nomes gregos normalmente chegam em português através de sua forma latina. Na passagem do latim para o português, -tia se torna -cia.
} 
primeiro livro organizado no Brasil sobre o filósofo (n. 137). É interessante observar que os estudos proclianos brasileiros têm se desenvolvido em universidades da região nordeste, especialmente a Universidade Federal do Rio Grande do Norte (UFRN), a Universidade Federal do Ceará (UFC) e a Universidade Federal de Sergipe (UFS). Em 2010, foi defendida a primeira tese de doutorado no Brasil que fazia um estudo comparativo entre Plotino, Jâmblico e Damáscio, conforme consta no Primeiro repertório. Depois disso, nada mais foi publicado sobre Damáscio, de acordo com nossos registros. Por outro lado, recrudesceram os estudos sobre Jâmblico. Foram catalogados 15 textos dos quais 1 capítulo de livro (n. 68), 3 dissertações de mestrado (n. 31, 126 e 162), 1 tese de doutorado (n. 36) e o restante se resume a artigos. Um autor várias vezes citado no Primeiro repertório, Boécio, por sua vez, segue sendo bastante estudado, verificando-se 14 ocorrências neste repertório. Destaca-se a tradução de $A$ consolação da filosofia (n. 124).

É digna de atenção a publicação de mais de 70 trabalhos sobre Plotino. O Licopolitano segue, assim, sendo o filósofo neoplatônico mais estudado em português. A cada passo, veios novos nos surpreendem. No âmbito das traduções do pensamento de Plotino, 3 foram publicadas em âmbitos ainda pouquíssimo estudados no Brasil. Em 2010, a Enéada II: a organização do cosmo; tradução, introdução e notas de João Lupi, (n. 22). O tratado Sobre a eternidade e o tempo (III, 7 [45]), com introdução, tradução e notas por José Carlos Baracat Jr., veio a lume em 2014 (n. 101). Em 2015, Maria Aparecida de Oliveira Silva viu publicada sua tradução de Do amor: Enéada III, 5 (n. 120). É indubitável o valor dessas traduções diretas do grego. Feito significativo foi a edição, em 2013, do Dossiê Plotino, na Revista Archai, n. 10, capitaneado por Loraine Oliveira, reunindo 7 artigos em português sobre o "velho homem", como o nomearam os islâmicos medievais (n. 76).

Três livros sinalizando diferentes rumos à hermenêutica dos textos de Plotino foram traduzidos: o de Thomas Alexander Szlezák, Platão e Aristóteles na doutrina do noûs de Plotino, com tradução de Monika Ottermann, veio a lume em 2010 (n. 27); A metafísica de Plotino, de autoria de Jean-Marc Narbonne, traduzido por Maurício Pagotto Marsola e publicado em 2014 (n. 100); e, em 2019, uma obra fundamental de Pierre Hadot: Plotino ou a simplicidade do olhar, traduzido por Loraine Oliveira e Flávio Fontenelle Loque, com breve apresentação escrita pela tradutora. Apesar da pouca valorização do trabalho dos tradutores, gostaríamos de ressaltar aqui a necessidade de tais traduções e a relevância de que sejam efetuadas por pesquisadores da área; fazemos assim votos de que muitas outras venham a ser realizadas.

É mister observar a atenção póstuma no Brasil conferida a Pierre Hadot que, no século XX, elaborou uma tese original sobre a filosofia antiga, além de se ter dedicado a exaustivos estudos sobre o neoplatonismo, máxime Plotino, Porfírio e Mário Vitorino. O acesso às obras de Hadot em língua portuguesa é vital para a formação de um vocabulário técnico lusófono e para as futuras gerações de estudantes e pesquisadores que terão à disposição em sua própria língua obras essenciais da historiografia hodierna sobre Plotino e a sua escola. Além do já mencionado Plotino ou a simplicidade do olhar, foram ainda traduzidos outros livros do estudioso. Especial destaque deve ser dado ao já clássico livro Exercícios espirituais e filosofia antiga, no qual é desenvolvida sua tese sobre a filosofia antiga "(...) como um método de formação de uma nova maneira de viver e de ver o mundo, como um esforço 
de transformação do homem". ${ }^{4}$ Nesta obra, Plotino, Porfírio e o neoplatonismo antigo são extensamente comentados. Do mesmo autor ainda podem-se mencionar as traduções de: Elogio da filosofia antiga; Elogio de Sócrates; A filosofia como maneira de viver e Wittgenstein e os limites da linguagem. ${ }^{5}$ Igualmente cabe rememorar a tradução do artigo de Philippe Hoffmann, por Luciana Gabriela Soares Santoprete, intitulado "Pierre Hadot (1922-2010), In memoriam", ${ }^{6}$ que retraça o percurso intelectual de Hadot.

Uma temática muito atual nos estudos sobre Plotino vem ganhando espaço, a saber, a questão das relações entre o pensamento plotiniano e os gnósticos. Em 2018 foi publicado um livro intitulado Estratégias antignósticas nos escritos de Plotino, mas, em razão das dificuldades de difusão, tomamos conhecimento dessa obra somente após o fechamento deste Repertório. O volume é constituído de 6 artigos, sendo dois em português: o de Daniela P. Taormina, "Plotino: memória dos inteligíveis e experiência do belo. Um argumento contra os gnósticos" (p. 13-28), traduzido por Maurício Marsola, e o dele próprio, "Os 'homens divinos' no contexto polêmico de 33 (II 9) 6" (p. 49-74).?

Os eventos sobre neoplatonismo no Brasil não foram mencionados no repertório, mas serão divulgados no blog de pesquisa Les Platonismes de l'Antiquité Tardive. ${ }^{8}$ Aproveitamos a ocasião para convidar os colegas a promoverem neste blog seus eventos enviando um e-mail para platonismes@gmail.com

Cumpre, ademais, agradecer a Albérico Araújo Sial Neto, estudante de Filosofia da Universidade Federal de Pernambuco (UFPE), que diligentemente fez os gráficos aqui incluídos e acautelou-nos contra Titivillus, revisando o repertório.

Ao término, esperamos que esta ferramenta de consulta bibliográfica lusófona sobre o neoplatonismo antigo faça florescer vindouros estudos neoplatônicos em terra brasilis.

\footnotetext{
${ }^{4}$ HADOT, P. Exercícios espirituais e filosofia antiga. São Paulo: É Realizações, 2014, p. 64.

${ }^{5}$ Eis as referências completas em ordem de ano de publicação: HADOT, P. Elogio da filosofia antiga. Tradução Flávio Fontenelle Loque e Loraine Oliveira. São Paulo: Loyola, 2012; HADOT, P. Elogio de Sócrates. Tradução Loraine Oliveira e Flávio Fontenelle Loque. São Paulo: Loyola, 2012; HADOT, P. Exercicios espirituais e filosofia antiga. Tradução Flávio Fontenelle Loque e Loraine Oliveira. São Paulo: É Realizações, 2014; HADOT, P. Wittgenstein e os limites da linguagem. Tradução Flávio Fontenelle Loque e Loraine Oliveira. São Paulo: É Realizações, 2014; HADOT, P. A filosofia como maneira de viver. Entrevistas de Jeanne Carlier e Arnold I. Davidson. Tradução Lara Christina de Malimpensa. São Paulo: É Realizações, 2016; HADOT, P. Plotino ou a simplicidade do olhar. Tradução Loraine Oliveira e Flávio Fontenelle Loque. São Paulo: É Realizações, 2019. Vale ainda notar que já está em estágio avançado de preparação por Luciana Gabriela Soares Santoprete a tradução do livro de Michel Tardieu, Recherches sur la formation de l'Apocalypse de Zostrien et les sources de Marius Victorinus, e de Pierre Hadot, Porphyre et Victorinus. Questions et réponses, Bures-sur-Yvette, GECMO (Res Orientales 9), 1996.

${ }^{6}$ HOFFMANN, Phillipe: "Pierre Hadot (1922-2010), In memoriam". Tradução: SANTOPRETE, Luciana G. Soares. Archai, n. 18, 2016, p. 291-316.

${ }^{7}$ MARSOLA, Maurício Pagotto; FERRONI, Lorenzo (eds.) Estratégias antignósticas nos escritos de Plotino. São Paulo: Annablume, 2018. https://www.academia.edu/40198388/Estrat\%C3\%A9gias_anti_ gn $\%$ C $3 \%$ B3sticas_nos_escritos_de_Plotino

${ }^{8}$ Cf. https://platonismes.huma-num.fr/
} 


\section{Catálogo de aUtores e títulos}

\section{8}

1. PLOTINO. Acerca do Bem ou do Uno: Enéada VI, 9 - Tratado 9. Introdução, tradução e notas: SILVEIRA, Paulo Henrique Fernandes. Revista Integração, n. 53, p. 175-86, 2008. Disponível em: http://imagomundi.com.br/filo/plotino_eneade_trat_09.pdf. Acesso em: 11/09/2018.

2. REIS, José. Sobre o tempo: Aristóteles, Plotino, Santo Agostinho, Kant, Bergson, Husserl, Heidegger: conclusões. Porto: Editora Afrontamento, 2008.

3. ULLMANN, Reinhold Aloysio. Plotino: um estudo das Enéadas. Porto Alegre: EDIPUCRS, 2008.

\section{9}

4. DZIELSKA, Maria. Hipátia de Alexandria. Tradução: PEREIRA, Miguel Serras. Lisboa: Relógio d'Água, 2009.

5. MOTA, Bernardo Machado. Proclo e a fundamentação epistemológica da geometria euclidiana. Euphrosyne. Revista de filologia clássica, n. 37, p. 69-92, 2009. Disponível em: https:/ / dialnet.unirioja.es/servlet/articulo?codigo $=2917134$

\section{0}

6. BARACAT JUNIOR, José Carlos. O limite do discurso em Plotino. In: PINHEIRO, Marcus Reis; BINGEMER, Maria Clara (orgs.). Mistica e Filosofia. 1a ed. Rio de Janeiro: PUC-Rio/UAPE, 2010, p. 99-116.

7. BEZERRA, Cícero Cunha. Unidade e pensamento no Parmênides e nos Elementos de Teologia de Proclo. Archai: Revista de Estudos sobre as Origens do Pensamento Ocidental, v. 5, n. 5, p. 91-104, 2010.

Disponível em: https://periodicos.unb.br/index.php/archai/article/view/2936. Acesso em: 10/09/2019.

8. BRANDÃO, Bernardo G. S. L. A contemplação mística do Um em Plotino. Sapere Aude, v. 1, n. 2, p. 7-19, 2010. Disponível em: http://periodicos.pucminas.br/index. php/SapereAude/article/view/1297/2263. Acesso em: 10/09/2018.

9. CARVALHO, Margarida Maria de. Um caso político-cultural na Antiguidade Tardia: o Imperador Juliano e seu conceito de educação. Acta Scientiarum. Education, v. 32, n. 1, p. 27-39, 2010. Disponível em: http://periodicos.uem.br/ojs/index.php/ActaSciEduc/ article/view/9488/5878. Acesso em: 10/09/2018.

10. COHEN, Daniel; LACROSSE, Joachim. A filosofia do mito em Plotino e Proclo. Um estudo comparativo. Tradução: SOUZA Aláya Dullius de. Archai: Revista de Estudos sobre as Origens do Pensamento Ocidental, n. 5, p. 77-82, 2010. Disponível em: https:/ / periodicos. unb.br/index.php/archai/article/view/2933. Acesso em: 10/09/2018. 
11. FERREIRA, Ana Rita de Almeida Araújo Francisco. Do belo: a estética augustiniana vista à luz das Enéadas. Signum Revista da ABREM, v.. 11, n. 1, p. 3-25, 2010. Disponível em: http://www.abrem.org.br/revistas/index.php/signum/article/view/1. Acesso em: 10/09/2020.

12. FERREIRA, Elisa Franca e. O homem a caminho do Uno nas Enéadas de Plotino: as vias do músico, do amante e do filósofo. Archai: Revista de Estudos sobre as Origens do Pensamento Ocidental, n. 5, p. 59-65, 2010. Disponível em: https://periodicos.unb.br/ index.php/archai/article/view/2931. Acesso em: 10/09/2020.

13. FIGUEIREDO, Daniel de. Cultura política no século IV d.C.: Imperador Juliano, anacrônico e perseguidor de cristãos? In: XVII Encontro Regional de História (ANPUH$M G)$. Uberlândia: 2010.

14. GONÇALVES, Ana Teresa Marques; VIEIRA, Ivan. Religião e magia na Antiguidade Tardia: do helenismo ao neoplatonismo de Jâmblico de Cálcis. Dimensões, Revista de História da UFES, v. 25, p. 4-17, 2010. Disponível em: http://www.periodicos.ufes.br/ dimensoes/article/view/2539/2035. Acesso em: 10/09/2018.

15. GOULET-CAZÉ, Marie-Odile. Dois tratados plotinianos em Eusébio de Cesaréia. Tradução: OLIVEIRA, Loraine; BARACAT JUNIOR, José Carlos. Archai: Revista de Estudos sobre as Origens do Pensamento Ocidental, n. 5, p. 11-28, 2010. Disponível em: https:// periodicos.unb.br/index.php/archai/article/view/2926. Acesso em: 10/09/2020.

16. GROISARD, Jocelyn. Plotino e o problema da mistura. Tradução: BARACAT JUNIOR, José Carlos. Archai: Revista de Estudos sobre as Origens do Pensamento Ocidental, n. 5, p. 37-48, 2010. Disponível em: https://periodicos.unb.br/index.php/archai/ article/view/2928/2630. Acesso em: 10/09/2020.

17. MARSOLA, Mauricio Pagotto. De Parmênides ao Parmênides e retorno: um aspecto da exegese plotiniana (V 1 [10] 8, 1-27). In: TAORMINA, Daniela Patrizia; O’MEARA, Dominic J.; RIEDWEG, Christoph (orgs.). L'essere del pensiero. Saggi sulla filosofia di Plotino. 1a ed. Napoli: Bibliopolis, 2010, p. 221-46.

18. NETO, Ivan Vieira. Filosofia, religião e misticismo na Antiguidade Tardia: Plotino, Porfírio e Jâmblico e as diferentes nuances do neoplatonismo. Archai: Revista de Estudos sobre as Origens do Pensamento Ocidental, n. 5, p. 129-36, 2010. Disponível em: https:// periodicos.unb.br/index.php/archai/article/view/2939. Acesso em: 11/09/2020.

19. OLIVEIRA, Loraine. Neoplatonismo antigo. Archai: Revista de Estudos sobre as Origens do Pensamento Ocidental, n. 5, jul. 2010. Disponível em:

https://periodicos.unb.br/index.php/archai/article/view/2925/2627. Acesso em: 10/09/2020

20. OLIVEIRA, Maria Eduarda Martins de. A fraternidade entre alma do mundo e almas individuais na Filosofia de Plotino. Dissertação (Mestrado em Filosofia) - Programa de Pós-Graduação em Filosofia da Universidade de São Paulo, São Paulo, 2010. Disponível em: http://www.teses.usp.br/teses/disponiveis/8/8133/tde-24082010-144425/pt-br. php. Acesso em: 10/09/2020. 
21. PINHEIRO, Marcus Reis. Inconsciente, consciente e cosmologia em Plotino. Archai: Revista de Estudos sobre as Origens do Pensamento Ocidental, n. 5, p. 49-58, 2010. Disponível em: https://digitalis.uc.pt/pt-pt/artigo/inconsciente_consciente_e_cosmologia_em_ plotino. Acesso em: 10/09/2020.

22. PLOTINO. Enéada II: a organização do cosmo. Tradução, introdução e notas: LUPI, João. Petrópolis: Vozes, 2010.

23. SANTOS, David G. Plotino e Ireneu de Lyon contra os gnósticos: uma proposta paralela? Diferenças e paralelismos do contragnosticismo de Ireneu e de Plotino. Archai: Revista de Estudos sobre as Origens do Pensamento Ocidental, n. 5, p. 105-18, 2010. Disponível em: https://periodicos.unb.br/index.php/archai/article/view/2937. Acesso em: 10/09/2020.

24. SAVIAN FILHO, Juvenal. A metafísica de Boécio e a noção de haecceitas em Duns Escoto. Signum Revista da ABREM, v. 11, n. 2. p. 1-19, 2010. Disponível em:

http://www.abrem.org.br/revistas/index.php/signum/article/view/19. Acesso em: $11 / 09 / 2018$.

25. SAVIAN FILHO, Juvenal. Boécio (Verbete). In: BARRETTO, Vicente de Paulo; CULLETON, Alfredo (orgs.). Dicionário de filosofia política. São Leopoldo: UNISINOS, 2010, p. 73-6.

26. SILVA, Gonçalo Ferreira da. Hipátia: guardiã da ciência, heroína e mártir. Rio de Janeiro: Academia brasileira de literatura de cordel, 2010. Disponível em: http:/ / docvirt.com/ docreader.net/DocReader.aspx?bib $=$ cordel\&pagfis $=85287$. Acesso em: 10/09/2018.

27. SZLEZÁK, Thomas Alexander. Platão e Aristóteles na doutrina do noûs de Plotino. Tradução: OTTERMANN, Monika. São Paulo: Paulus, 2010.

28. BARACAT JUNIOR, José Carlos. Imperador Juliano, Contra os Galileus: introdução biográfica, tradução e notas. Cadernos de Tradução, n. 27, p. 1-72, 2011. Disponível em: https://www.academia.edu/3846700/_Ed_Imperador_Juliano_Contra_os_Galileus_ introdução_biográfica_tradução_e_notas_Emperor_Julian_Against_the_Galileans_ introduction_translation_and_notes_Cardenos_de_Tradução_27_UFRGS_. Acesso em: 11/09/2018.

29. FERNANDES, Marcos Aurélio. A árvore de Porfírio: Comentários à Isagoge. Scintilla, Revista de filosofia e mística medieval, v. 8, n. 1, p. 11-44, 2011.

30. NASCIMENTO, Marlo do. A questão da felicidade na Consolação da filosofia. In: VASCONCELLOS, Manoel; SILVA, Lucas (orgs.). Studia Mediaevalia. 1a ed. Pelotas: Cópias Santa Cruz, 2011, p. 17-25.

31. NETO, Ivan Vieira. O paganismo neoplatônico de Jâmblico de Cálcis: a influência religiosa na filosofia tardo-antiga (sécs. III e IV d.C.). Dissertação (Mestrado em História) - Programa de Pós-Graduação em História da Universidade Federal de Goiás, Goiânia, 2011. 
32. OLIVEIRA, Janduí Evangelista de; COSTA, Marcos Roberto Nunes. O problema de Deus na filosofia de Plotino: convergências e divergências com o Deus judaico-cristão. Perspectiva Filosófica, v. 1, n. 35, p. 25-38, 2011. Disponível em: https://www3.ufpe.br/ ppgfilosofia/images/pdf/2011.1\%20-\%20medieval.pdf. Acesso em: 11/09/2018.

33. OLIVEIRA, Loraine. Considerações sobre o uso adequado do termo "mística" na filosofia de Plotino. Perspectiva Filosófica, v. 1, n. 35, p. 55-71, 2011. Disponível em: https://www3.ufpe.br/ppgfilosofia/images/pdf/2011.1\%20-\%20medieval.pdf. Acesso em: 11/09/2018.

34. REEGEN, Jan Gerard Joseph ter. A mística em Proclo. Perspectiva Filosófica, v. 1, n. 35, p. 9-24, 2011. Disponível em: https://www3.ufpe.br/ppgfilosofia/images/ pdf/2011.1\%20-\%20medieval.pdf. Acesso em: 11/09/2018.

35. SANTOS, Vanessa Alves de Lacerda. Mito: entre a reflexão do real e o reflexo do inteligível. Saberes: Revista Interdisciplinar de Filosofia e Educação, v. 3, n. esp, p. 214-22, 2011. Disponível em: https://periodicos.ufrn.br/saberes/article/view/889. Acesso em: 11/09/2018.

36. SILVA, Josildo José Barbosa da. Eram realmente Pitagórico(a)s os homens e mulheres catalogado(a)s por Jâmblico em sua obra Vida de Pitágoras? Tese (Doutorado em Educação) - Programa de Pós-Graduação em Educação da Universidade Federal do Rio Grande do Norte, Natal, 2011. Disponível em: https://repositorio.ufrn.br/jspui/ bitstream/123456789/14334/1/JosildoJBS_TESE.pdf. Acesso em: 11/09/2018.

37. SOUZA, Aláya Dullius de. O Apócrifo de João e a Enéada VI 9 de Plotino: relações sobre o Um. Dissertação (Mestrado em Filosofia) - Programa de Pós-Graduação em Filosofia da Universidade de Brasília, Brasília, 2011. Disponível em: http:/ / repositorio.unb.br/ handle/10482/10242. Acesso em: 11/09/2018.

2012

38. ALCÂNTARA, Antônio Carlos Kondracki de. O processo de conversão a deus pela via racional e mistica. Tese (Doutorado em Filosofia) - Programa de Pós-Graduação em Filosofia da Pontifícia Universidade Católica do Rio Grande do Sul, Porto Alegre, 2012. Disponível em: http://tede2.pucrs.br/tede2/handle/tede/2890. Acesso em: 11/09/2018.

39. BRANDÃO, Bernardo G. S. Lins. Ascensão e virtude em Plotino. Tese (Doutorado em Filosofia) - Programa de Pós-Graduação em Filosofia da Universidade Federal de Minas Gerais, Belo Horizonte, 2012. Disponível em: https://repositorio.ufmg.br/ bitstream/1843/BUOS-99GJDV/1/tese._mi_stica_e_filosofia_em_plotino_2012_. pdf. Acesso em: 10/09/2020.

40. CASTRO, José Acácio Aguiar de. Plotino - uma estética do inefável. Theologica, II série, v. 47, fasc. 2, p. 509-19, 2012. Disponível em: https://repositorio.ucp.pt/ bitstream/10400.14/13384/1/castro.pdf. Acesso em: 10/09/2018. 
41. CORNELLI, Gabriele. O belo antro e a grande oliveira: recepções da alegoria da caverna na tradição neoplatônica. Educação e Filosofia, v. 26, n. 51, p. 93-112, 2012. Disponível em: http://www.seer.ufu.br/index.php/EducacaoFilosofia/article/view/8245. Acesso em: 10/09/2018.

42. COSTA, Helena Maria Ramos da. O inédito comentário de Luís de Molina sobre a Isagogé de Porfirio. O problema dos universais nas universidades portuguesas na transição do séc. XV I para o século XVII. Tese (Doutorado em Filosofia) - Programa Doutoral em Filosofia da Universidade do Porto, Porto, Portugal, 2012.

43. ÉVORA, Fátima Regina Rodrigues. Filopono de Alexandria e a controvérsia acerca da eternidade do mundo. In: LEVY, Lia; ZINGANO, Marco; PEREIRA, Luis Carlos (orgs.). Metafísica, lógica e outras coisas mais. 1a ed. Rio de Janeiro: NAU Editora, 2012, p. 65-96.

44. GOMES, Rafael Vieira. "Esoterismo" e conhecimento em Plotino. Kinesis. Revista de Estudos dos Pós-Graduandos em Filosofia, v. 4, n. 7. p. 134-49, 2012. Disponível em: https:/ / www.marilia.unesp.br/Home/RevistasEletronicas/Kinesis/rafaelgomes134-149.pdf. Acesso em: 10/09/2020.

45. FARIAS JÚNIOR, José Petrúcio de. Discurso, retórica e poder na Antiguidade Tardia: a construção do ethos político em Sinésio de Cirene. Tese (Doutorado em História) - Programa de Pós-Graduação em História da Universidade Estadual Paulista “Júlio de Mesquita Filho", Franca, 2012. Disponível em: https://repositorio.unesp.br/handle/11449/103104. Acesso em: 11/09/2018.

46. OLIVEIRA, Loraine. Entre o sensível e o inteligível: o estatuto intermediário da imaginação em Plotino. In: MARQUES, Marcelo Pimenta (org.). Teorias da imagem na Antiguidade. 1a ed. São Paulo: Paulus, 2012, p. 287-307.

47. PINHEIRO, Marcus Reis. Mística em Plotino. In: TEIXEIRA, Faustino (org.). Caminhos da Mistica. 1a ed. São Paulo: Paulinas, 2012, p. 19-36. Disponível em: https://www. academia.edu/1648154/M\%C3\%ADstica_em_Plotino-final. Acesso em: 10/09/2018.

48. PINHEIRO, Marcus Reis. Plotino entre Narciso e Odisseu: Jogos de espelhos e a nostalgia da casa. In: BEZERRA, Cícero Cunha; BAUCHWITZ, Oscar Federico (orgs.). Neoplatonismo: tradição e contemporaneidade. 1a ed. São Paulo: Hedra, 2012, p. 11 30. Disponível em: https://www.academia.edu/5403579/Plotino_entre_Narciso_e_ Odisseu_Jogos_de_espelhos_e_a_Nostalgia_da_casa. Acesso em: 10/09/2018.

\section{3}

49. BAL, Gabriela. A influência da $3^{a}$ hipótese do Parmênides de Platão na filosofia de Plotino e Jâmblico. Archai: Revista de Estudos sobre as Origens do Pensamento Ocidental, v. 10, n. 10, p. 113-25, 2013. Disponível em: https://periodicos.unb.br/index.php/archai/article/ view/8370. Acesso em: 10/09/2020. 
50. BARACAT JUNIOR, José Carlos. Exemplo ou contraexemplo? O caso de uma estátua nas Enéadas de Plotino. Archai: Revista de Estudos sobre as Origens do Pensamento Ocidental, v. 10, n. 10, p. 73-83, 2013. Disponível em: https://periodicos.unb.br/index.php/ archai/article/view/8366. Acesso em: 10/09/2020.

51. BERGONSO, Melissa Carla Chornobay. Número, som e beleza: a estética musical em Boécio. Dissertação (Mestrado em Música) - Setor de Ciências Humanas, Letras e Artes da Universidade Federal do Paraná, Curitiba, 2013. Disponível em: https:/ / acervodigital. ufpr.br/handle/1884/30451. Acesso em: 11/09/2018.

52. BEZERRA, Cícero Cunha; BAUCHWITZ, Oscar Federico (orgs.). Neoplatonismo: tradição e contemporaneidade. São Paulo: Hedra, 2013.

53. BEZERRA, Cícero Cunha. Breves considerações sobre o belo em Plotino. In: SERRÃO, Adriana Veríssimo; SIMÕES, Carla Meneses (eds.). Poética da Razão-Homenagem a Leonel Ribeiro dos Santos. 1a ed. Lisboa: Centro de Filosofia da Universidade de Lisboa, 2013, p. 331-6.

54. BOÉCIO. A consolação da filosofia. Tradução: LI, Willian. 2a ed. São Paulo: WMF Martins Fontes, 2013.

55. BRANDÃO, Bernardo G. S. L. A filosofia como modo de vida no platonismo da era imperial e em Plotino. Mirabilia. Electronic Journal of Antiquity \& Middle Ages, v. 17, n. 2, p. 523-44, 2013. Disponível em: http://www.revistamirabilia.com/sites/default/files/ pdfs/2013_02_22_0.pdf. Acesso em: 11/09/2018.

56. BRANDÃO, Bernardo G. S. L. Filosofia como modo de vida em Plotino. Diálogos Mediterrânicos, n. 4, p. 89-96, 2013. Disponível em: http://www.dialogosmediterranicos. com.br/index.php/RevistaDM/article/view/71. Acesso em: 10/09/2018.

57. BRANDÃO, Bernardo G. S. L. A noção de ascensão na filosofia de Plotino. Dois Pontos (UFPR), v. 10, n. 2, p. 55-74, 2013. Disponível em: https://revistas.ufpr.br/doispontos/ article/view/31899. Acesso em: 10/09/2018.

58. BRANDÃO, Bernardo G. S. L. As afecções e a alma impassível em Plotino. Hypnos, n. 31, p. 185-98, 2013. Disponível em: https://hypnos.org.br/index.php/hypnos/ article/view/164/166. Acesso em: 10/09/2020.

59. BRANDÃO, Bernardo G. S. L. Estados de consciência e níveis do eu em Plotino. Archai: Revista de Estudos sobre as Origens do Pensamento Ocidental, v. 10, n. 10, p. 95-102, 2013. Disponível em: https://periodicos.unb.br/index.php/archai/article/view/8368. Acesso em: 10/09/2020.

60. BRANDÃO, Bernardo G. S. L. O problema do misticismo em Plotino. Revista Estudos Filosóficos, n. 10, p. 29-39, 2013. Disponível em: https:/ / ufsj.edu.br/portal2-repositorio/ File/art3-rev10(1).pdf. Acesso em 10/09/2020.

61. BRISSON, Luc. A oposição phúsis/tékhne em Plotino. Tradução: OLIVEIRA, Loraine; FONTENELLE, Flávio Loque. Archai: Revista de Estudos sobre as Origens do Pensamento Ocidental, v. 10, n. 10, p. 63-72, 2013.Disponível em: https://periodicos.unb.br/index. php/archai/article/view/8365. Acesso em: 10/09/2020. 
62. CARVALHO, Margarida Maria de. O Imperador Juliano entre a filosofia neoplatônica e a arte militar. Revista Territórios e Fronteiras, v. 6, n. 1, p. 18-31, 2013. Disponível em: http:/ / www.ppghis.com/territorios\&fronteiras/index.php/v03n02/article/view/190/144. Acesso em: 10/09/2018.

63. CARVALHO, Margarida Maria de; FIGUEIREDO, Daniel. O significado do "contra" nos discursos político-religiosos da Antiguidade Tardia: o "Contra os Galileus" do Imperador Juliano - 361-363 d.C. In: CERQUEIRA, Fábio; GONÇALVES, Ana Teresa; MEDEIROS, Edalaura; LEÃO, Delfim (orgs.). Saberes e poderes no mundo antigo. Estudos ibero-latino-americanos. Vol. II - dos poderes. 1a ed. Coimbra: Imprensa da Universidade de Coimbra, 2013, p. 213-26. Disponível em: https://digitalis.uc.pt/ handle/10316.2/34762. Acesso em: 10/09/2018.

64. COELHO, Cleber Duarte. O perfil do feminino na Consolação de Boécio. In: CÂNDIDO, Edinei da Rosa (org.). A mulher na Antiguidade Cristã. 1a ed. Florianópolis: ITESC, FACASC, 2013, p. 315-19.

65. COSTA, Marcos Roberto Nunes. A influência do neoplatonismo na solução agostiniana do mal. In: BEZERRA, Cícero Cunha; BAUCHWITZ, Oscar Federico (org.). Neoplatonismo: tradição e contemporaneidade. 1a ed. v. 1. São Paulo: Hedra, 2013, p. 25-36.

66. FARIAS JÚNIOR, José Petrúcio de. A construção literária dos germanos por Sinésio de Cirene: marcas de repulsa e integração em De Regno e De Providentia. Classica. Revista Brasileira de Estudos Clássicos, v. 26, n. 2, p. 29-53, 2013. Disponível em: https:/ / revista. classica.org.br/classica/article/view/262. Acesso em: 10/09/2020.

67. FERNANDES, Edrisi. A "superação" schellinguiana do entendimento plotiniano da transição do bem para a matéria e o mal. Archai: Revista de Estudos sobre as Origens do Pensamento Ocidental, v. 10, n. 10, p. 127-40, 2013. Disponível em: https://periodicos. unb.br/index.php/archai/article/view/8371. Acesso em: 10/09/2020.

68. FINAMORE, John F. Jâmblico e o irracional: a continuidade da uma tradição platônica. In: AZAR FILHO, Celso Martins; PINHEIRO, Marcus Reis (orgs.). Neoplatonismo, mística e linguagem. 1a ed. Niterói: UFF, 2013, p. 15-43.

69. GATTI, Icaro Francesconi. A Crestomatia de Proclo: tradução integral, notas e estudo da composição do códice 239 da Biblioteca de Fócio. Dissertação (Mestrado em Letras Clássicas) - Programa de Pós-Graduação em Letras Clássicas da Universidade de São Paulo, São Paulo, 2013. Disponível em: http:/ / www.teses.usp.br/teses/disponiveis/8/8143/tde05062013-112806/pt-br.php. Acesso em: 11/09/2018.

70. GOMES, Rafael Vieira. Fuga e assimilação em Plotino: questões de ética e metafísica nas Enéadas. Dissertação (Mestrado em Filosofia) - Programa de Pós-Graduação em Filosofia da Universidade Federal de São Paulo, Guarulhos, 2013. Disponível em: https:// repositorio.unifesp.br/handle/11600/39306. Acesso em: 11/09/2018. 
71. LIMA, Fernanda Lemos de. Jâmblico de Cálcis, uma abordagem introdutória ao filósofo do neoplatonismo. Principia. Revista do Departamento de Letras Clássicas e Orientais do Instituto de Letras da UERJ, n. 26, p. 35-48, 2013. Disponível em: http://www.e-publicacoes. uerj.br/index.php/principia/article/view/7680/5544. Acesso em: 11/09/2018.

72. MOREIRA, Júlio César. Filosofia e teurgia no De Mysteriis de Jâmblico: um estudo dos livros I, II e III. Dissertação (Mestrado em Filosofia) - Programa de Estudos Pós-Graduação em Filosofia da Pontifícia Universidade Católica de São Paulo, São Paulo, 2013. Disponível em: https://tede2.pucsp.br/handle/handle/11628. Acesso em: 11/09/2018.

73. NARBONNE, Jean-Marc. A "lógica" da mística plotiniana. In: AZAR FILHO, Celso Martins; PINHEIRO, Marcus Reis (orgs.). Neoplatonismo, mistica e linguagem. 1 a ed. Niterói: UFF, 2013, p. 43-71.

74. NASCIMENTO, Marlo do. A questão da felicidade em Boécio. Dissertação (Mestrado em Filosofia) - Programa de Estudos Pós-Graduação em Filosofia. Universidade Federal de Pelotas, Pelotas, 2013. Disponível em: http://guaiaca.ufpel.edu.br:8080/handle/ prefix/5045. Acesso em: 11/09/2018.

75. OLIVEIRA, Loraine. O amor como estado da alma (páthos) em Plotino. Archai: Revista de Estudos sobre as Origens do Pensamento Ocidental, v. 10, n. 10, p. 85-94, 2013. Disponível em: https://periodicos.unb.br/index.php/archai/article/view/8367. Acesso em: 10/09/2020.

76. OLIVEIRA, Loraine (ed.). Dossiê Plotino. Archai: Revista de Estudos sobre as Origens do Pensamento Ocidental, v. 10, n. 10, p. 59-140, 2013. Disponível em: https://periodicos. unb.br/index.php/archai/article/view/8364.

77. OLIVEIRA, Loraine. Plotino, escultor de mitos. São Paulo: Annablume, 2013 (remissão ao n. 100).

78. OLIVEIRA, Loraine. Justificativas para o vegetarianismo em Porfirio de Tiro. In: UREIA, Rodrigo Frías. Cultura helenística y cristianismo primitivo: actualidades de un (des) encuentro. 1a ed. Santiago de Chile: Unesco, 2013, p. 39-52. Disponível em: https:// www.researchgate.net/publication/340296079_Justificativas_para_o_Vegetarianismo_ em_Porfirio_de_Tiro. Acesso em: 11/09/2018.

79. PAIVA, Marcello Henrique Medeiros de. Estética como ascensão para o Uno em Plotino. Dissertação (Mestrado em Filosofia) - Programa de Pós-Graduação em Filosofia da Universidade Federal do Rio Grande do Norte, Natal, 2013. Disponível em: https:/ / repositorio.ufrn.br/handle/123456789/21623. Acesso em: 11/09/2018.

80. PINHEIRO, Marcus Reis; AZAR FILHO, Celso Martins (orgs.). Neoplatonismo, mística e linguagem. Niterói: Editora da UFF, 2013.

81. PINHEIRO, Marcus Reis. O Uno em Parmênides e em Plotino. In: PINHEIRO, Marcus Reis; AZAR FILHO, Celso Martins (orgs.). Neoplatonismo, mistica e linguagem. $1 \mathrm{a}$ ed. Niterói: Editora da UFF, 2013, p. 71-88. Disponível em: https://www.academia. edu/1648155/O_Uno_em_Parmênides_e_em_Plotino. Acesso em: 10/09/2018. 
82. PINHEIRO, Marcus Reis. Cosmologia e transformação de si: o caso de Platão e Plotino. Cosmos e Contexto, v. 15, p. 1-10, 2013. Disponível em: http://cosmosecontexto.org.br/ cosmologia-e-transformacao-de-si-o-caso-de-platao-e-plotino. Acesso em: 11/09/2018.

83. RAMOS, Samuel Araújo. Antropofagizando os clássicos Vida pitagórica e O Banquete: caminhos percorridos e reflexões de um performer em busca de uma arte social e filosófica. Dissertação (Mestrado em Arte Contemporânea) - Programa de Pós-Graduação em Arte da Universidade de Brasília, Brasília, 2013. Disponível em: https://repositorio.unb.br/ handle/10482/14240. Acesso em: 11/09/2018.

84. SANTOS, Vanessa Alves de Lacerda. Ulisses e Narciso: as faces da alma humana através do discurso mítico nas Enéadas de Plotino. Dissertação (Mestrado em Filosofia) - Programa de Pós-Graduação em Filosofia. Universidade Federal do Rio Grande do Norte, Natal, 2013. Disponível em: https://repositorio.ufrn.br/handle/123456789/16512. Acesso em: 10/09/2020.

85. SANTOS, David G. Metafísica, ética e religião em Plotino: tradução e estudo da Enéada VI. 7 (38). Tese (Doutorado em Filosofia Antiga) - Faculdade de Letras da Universidade de Lisboa, Lisboa, Portugal, 2013. Disponível em: http://repositorio.ul.pt/ handle/10451/10555. Acesso em: 10/09/2020.

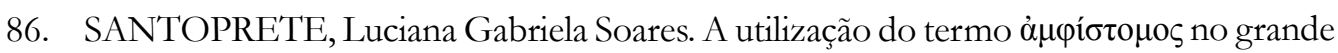
tratado antignóstico de Plotino e nos oráculos caldáicos. Archai: Revista de Estudos sobre as Origens do Pensamento Ocidental, v. 10, n. 10, p. 103-12, 2013. Disponível em: https:/ / periodicos.unb.br/index.php/archai/article/view/8369. Acesso em: 10/09/2020.

87. SAVIAN FILHO, Juvenal. Ser, unidade e bem em Boécio. In: BEZERRA, Cícero Cunha; BAUCHWITZ, Oscar Federico (orgs.). Neoplatonismo - tradição e contemporaneidade. 1a ed. São Paulo: Hedra, 2013, p. 97-110.

88. SILVA, Francisca Galiléia Pereira da; REEGEN, Jan Gerard Joseph Ter; CUNHA, Suelen Pereira da. Sobre a relação dinâmica da realidade supra-sensível segundo Proclo. Revista Kairós, v. 10, n. 2, p. 189-207, 2013. Disponível em: https://www. academia.edu/33633326/sOBRE_A_RELAÇÃO_DINÂMICA_DA_REALIDADE_SUPRA_ SENSÍVEL_SEGUNDO_PROCLO_SUR_LA_RELATION_DYNAMIQUE_DE_LA_RÉALITÉ_ SUPRASENSIBLE_SELON_PROCLUS. Acesso em: 10/09/2020.

89. SIMÕES, Vivian Carneiro Leão. Qvod erat demonstradvm - os exempla no discurso gramatical de Mário Vitorino. Dissertação (Mestrado em Estudos Literários) - Programa de Pós-Graduação em Estudos Literários da Universidade Estadual Paulista "Júlio de Mesquita Filho”, Araraquara, 2013. Disponível em: https://repositorio.unesp.br/ handle/11449/122095. Acesso em: 11/09/2018. 
90. BRANDÃO, Bernardo G. S. L. Ascensão e discurso em Plotino. Kriterion: Revista de Filosofia, v. 55, n. 130, p. 515-30, 2014. Disponível em: http://www.scielo.br/scielo. php?script=sci_arttext\&pid=S0100-512X2014000200004\&lng=en\&nrm=iso. Acesso em: 10/09/2018.

91. BRANDÃO, Bernardo G. S. L. Ascensão e virtude em Plotino. Sobre a doutrina dos níveis da virtude na Enéada I, 4. Gregorianum (Roma), v. 95, n. 1, p. 145-57, 2014. Disponível em: https://www.academia.edu/6388554/Ascensão_e_Virtude_em_ Plotino_-_Gregorianum_vo._95_n._1_-_2014. Acesso em: 10/09/2018.

92. BRANDÃO, Bernardo G. S. L. A doutrina da união em Plotino. Sapere Aude, v. 5, n. 10, p. 30-45, 2014. Disponível em: http://periodicos.pucminas.br/index.php/SapereAude/ article/view/8593. Acesso em: 10/09/2018.

93. FARIAS JÚNIOR, José Petrúcio de. Administração imperial e aquisição de poder na Antiguidade Tardia: agentes de poder sob a ótica de Sinésio. Mirabilia. Electronic Journal of Antiquity \& Middle Ages, v. 19, n. 2, p. 229-44, 2014. Disponível em: http://www. revistamirabilia.com/sites/default/files/pdfs/19-12varia.pdf. Acesso em: 10/09/2018.

94. FARIAS JÚNIOR, José Petrúcio de. Mito e história na Antiguidade Tardia: um estudo a partir de Sinésio de Cirene em De Regno. Fronteiras \& Debates, v. 1, n. 2, p. 141-63, 2014. Disponível em: https://periodicos.unifap.br/index.php/fronteiras/article/ view/2006/1088. Acesso em: 10/09/2018.

95. FARIAS JÚNIOR, José Petrúcio de. Filosofia, retórica e providência divina em De Providencia de Sinésio de Cirene. In: XVI Encontro Regional da ANPUH - Rio: Saberes e Práticas Cientificas. Rio de Janeiro: 2014, p. 1-21. Disponível em: http:// www.encontro2014.rj.anpuh.org/resources/anais/28/1400541072_ARQUIVO_ Filosofiaretoricaeprovindenciadivina.pdf. Acesso em: 11/09/2018.

96. LIMA, Fernanda Lemos de. A perene essência divina e a efêmera opinião: uma breve apreciação do livro I de Sobre os mistérios, de Jâmblico de Cálcis. Principia. Revista do Departamento de Letras Clássicas e Orientais do Instituto de Letras da UERJ, n. 29, p. 1-5, 2014. Disponível em: http:/ / www.e-publicacoes.uerj.br/index.php/principia/article/ view/14399/10919. Acesso em: 10/09/2018.

97. LIMA, Fernanda Lemos de. Agón epistolar: o debate filosófico-teúrgico no livro I de Sobre os mistérios, de Jâmblico de Cálcis. Calíope. Presença Clássica, v. 2, n. 28, p. 33-47, 2014. Disponível em: https://revistas.ufrj.br/index.php/caliope/article/view/7352/7122. Acesso em: 10/09/2018.

98. MOREIRA, Júlio Cesar. O caminho virtuoso e a teurgia de Jâmblico. Hypnos, v. 33, p. 315-23, 2014. Disponível em: https://hypnos.org.br/index.php/hypnos/article/ view/89/89. Acesso em: 10/09/2020.

99. NARBONNE, Jean-Marc. A metafísica de Plotino. Tradução: MARSOLA, Maurício Pagotto. São Paulo: Paulus, 2014. 
100. OlIVEIRA, Loraine. Plotino, escultor de mitos. Coimbra: Imprensa Universidade de Coimbra; Annablume, 2014 (remissão ao n. 77). Disponível em: https:/ / digitalis.uc.pt/ es/livro/plotino_escultor_de_mitos. Acesso em: 10/09/2018.

101. PLOTINO. Sobre a eternidade e o tempo (III, 7 [45]). Introdução, tradução e notas: BARACAT JUNIOR, José Carlos. In: PUENTE, Fernando Rey; BARACAT JUNIOR, José Carlos (orgs.). Tratados sobre o tempo. Aristóteles, Plotino e Agostinho. 1a ed. Belo Horizonte: Editora da UFMG, 2014, p. 53-100.

102. PUENTE, Fernando Rey; BARACAT JUNIOR, José Carlos (orgs.). Tratados sobre o tempo. Aristóteles, Plotino e Agostinho. Belo Horizonte: Editora da UFMG, 2014.

103. SANGALLI, Idalgo José. A conquista da felicidade via filosofia: o exemplo de Boécio. Trans/Form/Ação, Revista de Filosofia, v. 37, n. 3, p. 65-86, 2014. Disponível em: http:// www2.marilia.unesp.br/revistas/index.php/transformacao/article/view/4167/3041. Acesso em: 11/09/2018.

104. SILVA, Gilvan Ventura da. A cidade representada pelo poder imperial: Juliano e a censura à população de Antioquia no Misopogon. In: FLEMING, Maria Isabel D'Agostino (coord.). I Simpósio do Laboratório de Arqueologia Romana Provincial "Representações da romanização no mundo provincial romano", 27 a 29 de novembro de 2013, Faculdade de Educação - USP. Revista do Musen de Arqueologia e Etnologia, suplemento 18, 2014, p. 11-8.Disponível em: http://www.larp.mae.usp.br/AnaisLARP/Suplemento_18RevMAE-Anais-Simp-LARP.pdf. Acesso em: 11/09/2018.

105. SILVA, Ruan Fernandes da. Conhecimento de si e unidade: considerações sobre a alma em Plotino. Dissertação (Mestrado em Filosofia) - Programa de Pós-Graduação em Filosofia da Universidade Federal do Rio Grande do Norte, Natal, 2014. Disponível em: https:/ / repositorio.ufrn.br/handle/123456789/19709. Acesso em: 11/09/2018.

106. TAVARES, André Luís. A reelaboração da noção boeciana de pessoa na Summa Theologiae de Tomás de Aquino (Prima pars, quest. 29). Dissertação (Mestrado em Filosofia) - Programa de Pós-Graduação em Filosofia da Universidade Federal de São Paulo, Guarulhos, 2014. Disponível em: http:/ / repositorio.unifesp.br/handle/11600/39255. Acesso em: $11 / 09 / 2018$.

\section{5}

109. BEZERRA, Cícero Cunha. O uno plotiniano: liberdade e autorealização. In: BAUCHWITZ, Oscar Federico; FERNANDES, Edrisi; BEZERRA, Cícero (orgs.). Seminários do Seridó: solidão e liberdade. 1a ed. Natal: EDUFRN, 2015, p. 79-88.

108. BEZERRA, Cícero Cunha. Plotino e Agostinho de Hipona: considerações sobre o mal. In: SANTOS, Josalba Fabiana dos; JEHA, Julio (eds.). Sobre o mal. 1a ed. Curitiba: Appris, 2015, p. 175-83. 
109. BEZERRA, Cícero Cunha. O aspecto iniciático da poesia: Proclo e o Comentário à República de Platão. Numen: Revista de Estudos e Pesquisa da Religião, v. 18, n. 2, p. 17181, 2015. Disponível em: https://periodicos.ufff.br/index.php/numen/article/ view/22012. Acesso em: 10/09/2020.

110. BEZERRA, Cícero Cunha. Porfírio, Dionísio e mestre Eckhart: considerações sobre a adequação entre ser e inteligência. Princípios: Revista de Filosofia (UFRN), v. 22, n. 37, p. 31-51, 2015. Disponível em: https://periodicos.ufrn.br/principios/article/view/6889. Acesso em: 11/09/2018.

111. BRANDÃO, Bernardo L. A ascensão da alma nas Enéadas de Plotino. Revista de Filosofia, v. 40, n. 1, p. 29-44, 2015. Disponível em: http://revistas.ucm.es/index.php/RESF/ article/view/48438. Acesso em: 10/09/2018.

112. CARVALHO, Nathalia Ferreira de Avila. Da alteridade inerte à causalidade viva: sobre os sentidos de dúnamis a partir do tratado II.5 [25] das Enéadas de Plotino. Dissertação (Mestrado em Filosofia) - Programa de Pós-Graduação em Filosofia da Universidade Federal de Minas Gerais, Belo Horizonte, 2015. Disponível em: http:/ / hdl.handle.net/1843/ BUBD-9ZYHVM. Acesso: 29/10/19.

113. COSTA, Marcos Roberto Nunes da. O problema da moral no sistema ontológico cosmológico natural necessitário plotiniano. In: BAUCHWITZ, Oscar Federico; FERNANDES, Edrisi; BEZERRA, Cícero Cunha (orgs.). Seminários do Seridó: solidão e liberdade. 1a ed. Natal: EDUFRN, 2015, p. 281-92.

114. GAllego, Antonio Dopazo. Plotino: a odisseia da alma entre a eternidade e o tempo. Tradução: VELOSA, Filipa. Lisboa: Atlântico Press, 2015.

115. NASCIMENTO, Marlo do. Boécio e a questão do mal. In: XV Semana Acadêmica do Programa de Pós-Graduação em Filosofia da PUCRS, 2015, Porto Alegre. Semana Acadêmica do Programa de Pós-Graduação em Filosofia da PUCRS. Porto Alegre: v. 1, 2015, p. 267-79. Disponível em: http://www.editorafi.org/75semana. Acesso em: 11/09/2018.

116. OLIVEIRA, Janduí Evangelista; COSTA, Marcos Roberto Nunes da. O problema de identificação entre o Uno de Plotino com o Deus judaico-cristão. In: BAUCHWITZ, Oscar Federico; FERNANDES, Edrisi; BEZERRA, Cícero Cunha (orgs.). Seminários do Seridó: solidão e liberdade. 1a ed. Natal: EDUFRN, 2015, p. 173-89.

117. OLINTO, Carlos Alberto. A mistica de Plotino e a experiência religiosa do Agostinho de Cassiciaco: uma análise à luz de William James. Dissertação (Mestrado em Ciências da Religião) - Programa de Pós-Graduação em Ciências da Religião da Pontifícia Universidade Católica de Campinas, Campinas, 2015. Disponível em: http://tede. bibliotecadigital.puc-campinas.edu.br:8080/jspui/bitstream/tede/846/2/Carlos $\% 20$ Alberto\%20Olinto.pdf. Acesso em: 11/09/2018.

118. PAIVA, Marcello Henrique Medeiros de. Alma e liberdade em Plotino. In: BAUCHWITZ, Oscar Federico; FERNANDES, Edrisi; BEZERRA, Cícero Cunha (orgs.). Seminários do Seridó: solidão e liberdade. 1a ed. Natal: EDUFRN, 2015, p. 13-31. 
119. PIAUÍ, William de Siqueira; SILVA, Juliana Cecci. Comentário de Boécio ao $₫ 9$ do $D a$ Interpretação de Aristóteles. Prometeus, Filosofia em Revista, v. 8, n. 17, p. 187-206, 2015. Disponível em: http://seer.ufs.br/index.php/prometeus/article/view/2568/3059. Acesso em: 11/09/2018.

120. PLOTINO. Do amor: Enéada III, 5. Tradução: SILVA, Maria Aparecida de Oliveira. 1a ed. São Paulo: Edipro, 2015.

121. SILVA, Semíramis Corsi; FIGUEIREDO, Daniel. Mulheres no Império Romano da Antiguidade Tardia: considerações em torno da filósofa Hipátia de Alexandria. In: AMARAL, Fernanda Patarro; GONZÁLES MARTINEZ, María Nohemí (orgs.). Género y Ciencias Sociales: arqueologías y cartografías de fronteras. 1a ed. Barranquilla: Universidad Simón Bolivar, 2015, p. 251-80. Disponível em: https://www.academia. edu/22766513/G\%C3\%A9nero_y_Ciencias_Sociales._Arqueolog\%C3\%ADa_y_ cartograf\%C3\%ADas_de_fronteras. Acesso em: 10/19/2018.

122. SILVA, Adriano Martinho Correia da. A latinização do vocabulário grego do ser no de Hebdomadibus de Boécio. Dissertação (Mestrado em Filosofia) - Programa de PósGraduação em Filosofia da Universidade de São Paulo, São Paulo, 2015. Disponível em: http://www.teses.usp.br/teses/disponiveis/8/8133/tde-09102015-124551/pt-br. php. Acesso em: 11/09/2018.

\section{6}

123. BEZERRA, Cícero Cunha. Os theologikés stoicheiosis de Proclo e o Peri tes ouranias hierarchias de Dionísio Pseudo Areopagita: um diálogo possível. In: BEZERRA, Cícero Cunha; BATISTA DA SILVA, Nilo César (orgs.). Estudos de neoplatonismo e filosofia medieval. $1 \mathrm{a}$ ed. Curitiba: CRV, 2016, p. 49-64.

124. BOÉCIO. A consolação da filosofia. Tradução: LI, Willian. 2a ed. Lisboa: Calouste Gulbenkian, 2016.

125. CARVAlHO, Margarida Maria de; OMENA, Luciane Munhoz de. Considerações sobre memória e morte do imperador Juliano nos testemunhos de Libânio e Amiano Marcelino (século IV d.C.). Revista História, v. 35, p. 1-15, 2016. Disponível em: http:/ / www.scielo.br/pdf/his/v35/1980-4369-his-35-e84.pdf. Acesso em: 10/09/2018.

126. FONTES, Fabrício Soares Santos. As relações entre natureza e convenção em Antifonte e no Anônimo de Jâmblico. Dissertação (Mestrado em Filosofia) - Programa de Pós-Graduação em Filosofia da Universidade Federal de Minas Gerais, Belo Horizonte, 2016.

127. GOMES, Rafael Vieira. Fuga e assimilação em Plotino. Hypnos, n. 36, p. 129-43, 2016. Disponível em: https://hypnos.org.br/index.php/hypnos/article/view/478. Acesso em: 10/09/2020.

128. MARTINELLI, Águeda Vieira. Hypatia de Alexandria: por uma história não realizada. In: PACHECO, Juliana (org.). Filósofas: a presença das mulheres na filosofia. 1 a ed. Porto Alegre: Editora Fi, 2016, p. 64-83. Disponível em: http://www.editorafi.org/filosofas. Acesso em: 10/09/2018. 
129. NASCIMENTO, Marlo. Boécio e a Consolação da filosofia: Considerações acerca da virtude. Intuitio. Revista do PPG em Filosofia da PUCRS, v. 9, n. 1, p. 68-81, 2016. Disponível em: http://revistaseletronicas.pucrs.br/ojs/index.php/intuitio/article/ view/20531/14772. Acesso em: 19/10/2019.

130. NASCIMENTO, Tadeu Junior de Lima. Quando todos nós somos Um: A alteridade na filosofia de Plotino e sua possivel implicação ética. Dissertação (Mestrado em Ciências das Religiões) - Programa de Pós-Graduação em Ciências das Religiões da Universidade Federal da Paraíba, João Pessoa, 2016. Disponível em: https://repositorio.ufpb.br/ jspui/bitstream/123456789/11734/1/Arquivototal.pdf. Acesso em: 19/10/2020.

131. MARQUES, Rudinei dos Santos. A bénôsis plotiniana como exaltação da oralidade dialética de Platão. (Doutorado em Filosofia) - Programa de Pós-Graduação em Filosofia da Pontifícia Universidade Católica do Rio Grande do Sul, Porto Alegre, 2016. Disponível em: http://tede2.pucrs.br/tede2/handle/tede/6977. Acesso em: 29/10/2019.

132. OLIVEIRA, Loraine. Vestígios da vida de Hipácia de Alexandria. Perspectiva Filosófica, v. 43, n. 1, p. 3-20, 2016. Disponível em: https://periodicos.ufpe.br/revistas/ perspectivafilosofica/article/view/230301/24503. Acesso em: 11/09/2018.

133. SIMÕES, Vivian Carneiro Leão. De voce, de litteris, de syllabis nas Artes Grammaticae de Donato e de Mário Vitorino. Cadernos de Pós-Graduação em Letras, v. 16, n. 1, p. 51-67, 2016. Disponível em: http://editorarevistas.mackenzie.br/index.php/cpgl/article/ view/9529/5836. Acesso em: 11/09/2018.

\section{7}

134. FERNANDES, Mayã Gonçalves. Os tipos humanos e o caminho ascensional em Plotino. PHAINE: Revista de Estudos sobre Antiguidade, v. 2, n. 3, p. 80-93, 2017. Disponível em: https://periodicos.unb.br/index.php/phaine/article/view/7145/5781. Acesso em: 09/09/2020.

135. FERNANDES, Mayã Gonçalves. Representações da ninfa Calipso na Odisseia e sua interpretação em Plotino. Revista Contextura, v. 9, n. 10, p. 83-92, 2017. Disponível em: https://periodicos.ufmg.br/index.php/revistacontextura/article/view/3799. Acesso em: 09/09/2020.

136. LIMA, Fernanda Lemos de. A processão divina e os gêneros superiores no livro II de Sobre os Mistérios, de Jâmblico de Cálcis. Contemplação. Revista Acadêmica de Filosofia e Teologia da Faculdade João Paulo II, n. 15, p. 53-67, 2017. Disponível em: http:/ /www. fajopa.com/contemplacao/index.php/contemplacao/article/view/149. Acesso em: 10/09/2018. 


\section{8}

137. BAUCHWITZ, Oscar Federico (org.). Proclo: fontes e posteridade. 1a ed. Natal: Caule de Papiro, 2018. Disponível em: http://www.cchla.ufrn.br/ppgfil/PDF/publicacoesdiscentes/Livro_Proclo_fontes_e_posteridade $\% 20-\% 20$ Oscar_Federico_Bauchwitz. pdf

138. BAUCHWITZ, Oscar Federico. Proclo e o neoplatonismo medieval. In: BAUCHWITZ, Oscar Federico (org.). Proclo: fontes e posteridade. 1a ed. Natal: Caule de Papiro, 2018, p. 117-33.

139. BEZERRA, Cícero Cunha. Poesia e mistagogia: os comentários à República de Proclo. In: BAUCHWITZ, Oscar Federico (org.). Proclo: fontes e posteridade. 1a ed. Natal: Caule de Papiro, 2018, p. 33-53.

140. BRANDÃO, Bernardo L. Purificação e virtude em Plotino. In: OLIVEIRA, Loraine; BACELAR, Agatha. Cenas poéticas, filosóficas e musicais: um panorama dos estudos clássicos. 1a ed. São Paulo: Annablume, 2018, p. 157-73.

141. CUNHA, Suelen Pereira da. Identidade e alteridade como partes de um todo indissociável em Proclo. Dissertação (Mestrado em Filosofia) - Programa de Pós-Graduação em Filosofia da Universidade Federal do Ceará, Fortaleza, 2018. Disponível em: https://sucupira.capes. gov.br/sucupira/public/consultas/coleta/trabalhoConclusao/viewTrabalhoConclusao. jsf?popup $=$ true\&id_trabalho $=6429593$. Acesso em: 19/10/2019.

142. FERNANDES, Edrisi. Proclus Islamicus - a recepção de Proclo no mundo islâmico. In: BAUCHWITZ, Oscar Federico (org.). Proclo: fontes e posteridade. 1a ed. Natal: Caule de Papiro, 2018, p. 153-204.

143. FERNANDES, Mayã Gonçalves. O artista e o inteligivel: tipologia das artes em Plotino. Dissertação (Mestrado em Metafísica) - Programa de Pós-Graduação em Metafísica da Universidade de Brasília, Brasília, 2018. Disponível em: https://repositorio.unb. br/bitstream/10482/34644/1/2018_May\%C3\%A3Gon\%C3\%A7alvesFernandes.pdf. Acesso em: 10/09/2020.

144. LIMA, Danillo Costa. Conhecimento de si como caminho filosófico em Platão, Plotino e Proclo. Dissertação (Mestrado em Filosofia) - Programa de Estudos Pós-Graduação em Filosofia da Pontifícia Universidade Católica de São Paulo, São Paulo, 2018. Disponível em: https://tede2.pucsp.br/handle/handle/21491. Acesso em: 29/10/2019.

145. OLIVEIRA, Loraine. O significado do Porto do Pireu no Comentário à República I de Proclo. In: BAUCHWITZ, Oscar Federico (org.). Proclo: fontes e posteridade. 1a ed. Natal: Caule de Papiro: 2018, p. 9-33. Disponível em: http://www.cchla.ufrn.br/ ppgfil/PDF/publicacoes-discentes/Livro_Proclo_fontes_e_posteridade $\% 20-\% 20$ Oscar_Federico_Bauchwitz.pdf. Acesso em: 29/10/2019.

146. ROSSATTO, Noeli Dutra. Mestre Eckhart e a recepção dos comentários neoplatônicos ao Parmênides. In: BAUCHWITZ, Oscar Federico (org.). Proclo: fontes eposteridade. 1a ed. Natal: Caule de Papiro, 2018, p. 113-53. 
147. SILVA, Robert Brenner Barreto da. Internalidade e infalibilidade do intelecto no tratado V.5 das Enéadas de Plotino. Revista Primordium, v. 3, n. 6, p.1-8, 2018. Disponível em: http://www.seer.ufu.br/index.php/primordium/article/view/47192/26863. Acesso em: 10/10/2020.

148. SILVA, Robert Brenner Barreto da. Notas de leitura sobre o tratado V.3 (49) de Plotino: conceituação da hipóstase nous e delimitação da identidade entre intelecto e inteligíveis. Revista Seara Filosófica, n. 16, p. 89-102, 2018. Disponível em: https://periodicos.ufpel. edu.br/ojs2/index.php/searafilosofica/article/view/14151. Acesso em: 24/10/2019.

149. SILVA, Robert Brenner Barreto da. Breve estudo sobre a leitura de Plotino da geração do cosmos platônico. Contemplação. Revista Acadêmica de Filosofia e Teologia da Faculdade João Paulo II, n. 17, p. 128-40, 2018. Disponível em: http:/ /www.fajopa.com/contemplacao/ index.php/contemplacao/article/viewFile/176/194. Acesso em: 24/10/2019

150. SILVA, Robert Brenner Barreto da. Contexto da sophrosyne no Cármides e no I 2 de Plotino. Polymatheia - Revista de Filosofia, v. 11, n. 18, p. 66-89, 2018. Disponível em: http: / / seer.uece.br/?journal=PRF\&page $=$ article\&op $=$ view\&path $\% 5 B \% 5 \mathrm{D}=3269$. Acesso em: 29/10/2019.

\section{9}

151. ANDRADE, Thainan Noronha de. Francisco de Holanda e a influência do neoplatonismo em Portugal no século XVI. Dissertação (Mestrado em História) - Programa de PósGraduação em História da Universidade Federal de Minas Gerais, Faculdade de Filosofia e Ciências Humanas, Belo Horizonte, 2019. Disponível em: https:/ / repositorio.ufmg. br/bitstream/1843/BUOS-BC6FEJ/1/disserta__o__francisco_de_holanda_e_a_ influencia_do_neoplatonismo_em_portugal_no_s_culo_xvi_final_pdf. Acesso em: 24/10/2019.

152. SILVA, Robert Brenner Barreto da. A hipóstase noûs em Plotino: o itinerário teórico e o debate acerca do problema da identidade do Intelecto com as ideias na Enéada v. 3 [49]. Dissertação (Mestrado em Filosofia) - Programa de Pós-Graduação em Filosofia da Universidade Federal do Ceará, Fortaleza, 2019. Disponível em: http: / / repositorio.ufc.br/bitstream/ riufc/41013/7/2019_dis_rbbsilva.pdf. Acesso em: 24/10/2019.

153. SILVA, Robert Brenner Barreto da. A hipóstase noûs em Plotino: o itinerário teórico e o debate acerca do problema da identidade do intelecto com as ideias na Enéada v.3 [49]. Porto Alegre: Editora Fi, 2019. Disponível em: https:/ /www.editorafi.org/635robert

154. SILVA, Robert Brenner Barreto da. Por uma distinção entre pensamentos racional e intelectual no tratado v.3 [49] das Enéadas de Plotino. Guairacá - Revista de Filosofia, v. 35, n. 1, p. 75-86, 2019. Disponível em: https://revistas.unicentro.br/index.php/ guaiaraca/article/view/6169/4144. Acesso em: 24/10/2019 
155. COSTA, Marcos Roberto Nunes; COSTA, Rafael Ferreira. Hipátia de Alexandria (370-413 d.c). In: COSTA, Marcos Roberto Nunes; COSTA, Rafael Ferreira (orgs.). Mulheres intelectuais na Idade Média. 1a ed. Porto Alegre: Editora FI, 2019, p. 215-20. Disponível em: http:/ / livrandante.com.br/marcos-roberto-nunes-costa-rafael-ferreiracosta-mulheres-intelectuais-na-idade-media/. Acesso em: 29/10/2019.

156. FERNANDEZ, Cecília de Souza; AMARAL, Ana Maria Luz Fassarella do; VIANA, Isabela Vasconcellos (orgs). A história de Hipátia e de muitas outras matemáticas. Rio de Janeiro: Sociedade Brasileira de Matemática, 2019. Disponível em: https://www.sbm. org.br/wp-content/uploads/2019/05/ultimo.minicurso_historia_hipatia_muitas_ outras_matematicas.pdf. Acesso em: 24/10/2019.

157. HADOT, Pierre. Plotino on A simplicidade do olhar. Tradução: OLIVEIRA, Loraine; LOQUE, Flavio Fontenelle. São Paulo: É Realizações, 2019.

158. LEONARDI, Vinícius José Henrique da Costa. O belo enquanto esplendor do Um no tratado I, 6 de Plotino. Sapere Aude, v. 10, n. 19, p. 1-12, 2019. Disponível em: http:/ / periodicos.pucminas.br/index.php/SapereAude/article/view/19130. Acesso em: 24/10/2019.

159. OLIVEIRA, Loraine. "Fujamos então para a pátria querida": Plotino e a ascensão da alma humana. In: CURADO, Manuel; COUTINHO, Luciano; XAVIER, Dennys Coutinho (orgs.). Medicina e psicologia na Antiguidade: estudos de pensamento antigo. 1a ed. Ribeirão: Húmus, 2019, p. 305-22. Disponível em: https://www.academia. edu/40691313/_Fujamos_ent\%C3\%A3o_para_a_P\%C3\%A1tria_Querida_ Plotino_e_a_Ascens\%C3\%A3o_da_Alma_Humana. Acesso em: 21/10/2019.

160. HAUSCHILD, Álvaro Körbes. A doutrina do trabalho divino: a influência da teurgia dos Oráculos Caldeus sobre a filosofia de Jâmblico. Dissertação (Mestrado em Filosofia) Programa de Pós-Graduação em Filosofia da Universidade Federal do Rio Grande do Sul, Porto Alegre, 2019. Disponível em: https:/ /lume.ufrgs.br/handle/10183/190038. Acesso em: 24/10/2019.

\section{ÍNDICES}

\section{ÍNDICE POR AUTORES CONTEMPORÂNEOS}

ALCÂNTARA, Antônio Carlos Kondracki de, 38

AMARAL, Ana Maria Luz Fassarella do (org.), 158

AMARAL, Fernanda Patarro (org.), 121

ANDRADE, Thainan Noronha de, 151

AZAR FILHO, Celso Martins (org.), 68, 73, 80, 81

BAL, Gabriela, 49

BARACAT JUNIOR, José Carlos, 6, 28, 50

BARACAT JUNIOR, José Carlos (org.), 102

BARRETTO, Vicente de Paulo (org.), 25 
BATISTA DA SILVA, Nilo César (org.), 123

BAUCHWITZ, Oscar Federico, 138

BAUCHWITZ, Oscar Federico (org.), 48, 52, 65, 87, 107, 113, 116, 118, 137, 138, 139, 142, 145, 146 BERGONSO, Melissa Carla Chornobay, 51

BEZERRA, Cícero Cunha, 7, 53, 103, 107, 108, 109, 110, 123, 139

BEZERRA, Cícero Cunha (org.), 48, 52, 65, 87, 113, 114, 116, 118

BINGEMER, Maria Clara (org.), 6

BRANDÃO, Bernardo G. S. Lins, 8, 39, 55, 56, 57, 58, 59, 60, 90, 91, 92, 111, 140

BRISSON, Luc, 61

CÂNDIDO, Edinei da Rosá (org.), 64

CARVALHO, Margarida Maria de, 9, 62, 63, 125

CARVALHO, Nathália Ferreira de Avila, 108

CASTRO, José Acácio Aguiar de, 40

CERQUEIRA, Fábio (org.), 63

COELHO, Cleber Duarte, 64

COHEN, Daniel, 10

CORNELLI, Gabriele, 41

COSTA, Helena Maria Ramos da, 42

COSTA, Marcos Roberto Nunes, 32, 65, 113, 116, 155

CULLETON, Alfredo (org.), 25

CUNHA, Suelen Pereira da, 88, 141

DZIELSKA, Maria, 4

ÉVORA, Fátima Regina Rodrigues, 43

FARIAS JÚNIOR, José Petrúcio de, 45, 66, 93, 95

FERNANDES, Edrisi, 67

FERNANDES, Edrisi (org.), 107, 113, 116, 118, 142

FERNANDES, Marcos Aurélio, 29

FERNANDES, Mayã Gonçalves, 134, 135, 143

FERNANDEZ, Cecília de Souza (org.), 156

FERREIRA, Ana Rita de Almeida Araújo Francisco, 11

FERREIRA, Elisa Franca, 12

FIGUEIREDO, Daniel de, 13, 63, 121

GALLEGO, Antonio Dopazo, 114

GATTI, Icaro Francesconi, 69

GOMES, Rafael Vieira, 44, 70, 127

GONÇALVES, Ana Teresa Marques, 14

GONÇALVES, Ana Teresa (org.), 63

GONZÁLES MARTINEZ, María Nohemí (org.), 121

GOULET-CAZÉ, Marie-Odile, 15

GROISARD, Jocelyn, 16

HAUSCHILD, Álvaro Körbes, 160 
JEHA, Julio (ed.), 108

LACROSSE, Joachim, 10

LEÃO, Delfim (org.), 63

LEONARDI, Vinícius José Henrique da Costa, 158

LEVY, Lia (org.), 43

LIMA, Danillo Costa, 144

LIMA, Fernanda Lemos de, 71, 96, 97, 136

MARSOLA, Mauricio Pagotto, 17

MARTINELLI, Águeda Vieira, 128

MARQUES, Marcelo Pimenta (org.), 46

MARQUES, Rudinei dos Santos, 131

MEDEIROS, Edalaura (org.), 63

MOTA, Bernardo Machado, 5

MOREIRA, Júlio César, 72, 92

NARBONNE, Jean-Marc, 73, 99

NASCIMENTO, Marlo do, 30, 71, 115, 129

NASCIMENTO, Tadeu Junior, 130

NETO, Ivan Vieira, 18, 31

O'MEARA, Dominic J., (org.), 17

OMENA, Luciane Munhoz de, 125

OLINTO, Carlos Alberto, 117

OLIVEIRA, Maria Eduarda Martins de, 20

OLIVEIRA, Janduí Evangelista de, 32, 116

OLIVEIRA, Loraine, 15, 19, 33, 46, 61, 75, 76, 77, 100, 132, 140, 159.

PACHECO, Juliana (org.), 128

PAIVA, Marcello Henrique Medeiros de, 79, 118

PEREIRA, Luis Carlos (org.), 43

PIAUÍ, William de Siqueira, 119

PINHEIRO, Marcus Reis, 21, 47, 48, 68, 73, 80, 81, 82

PINHEIRO, Marcus Reis (org.), 6,

PUENTE, Fernando Rey (org.), 101, 102

RAMOS, Samuel Araujo, 85

REIS, José, 2

RIEDWEG, Christoph (org.), 17

REEGEN, Jan Gerard Joseph Ter, 34, 88

ROSSATTO, Noeli Dutra, 146

SANGALLI, Idalgo José, 105

SANTOS, David G., 23, 85

SANTOS, Vanessa Alves de Lacerda, 35, 84

SANTOS, Josalba Fabiana dos (ed.), 108

SANTOPRETE, Luciana Gabriela Soares, 86 
SEGUNDO REPERTÓRIO BIBLIOGRÁFICO DOS ESTUDOS EM LÍNGUA PORTUGUESA DEDICADOS

A PLOTINO E AO NEOPLATONISMO DA ANTIGUIDADE TARDIA

SAVIAN FILHO, Juvenal, 24, 25, 87

SERRÃO, Adriana Veríssimo (org.), 53

SILVA, Adriano Martinho Correia da, 122

SILVA, Francisca Galiléia Pereira da, 88

SILVA, Gilvan Ventura da, 104

SILVA, Gonçalo Ferreira da, 26

SILVA, Josildo José Barbosa da, 36

SILVA, Juliana Cecci, 119

SILVA, Lucas (org.), 30

SILVA, Robert Brenner Barreto da, 147, 148, 149, 150, 152, 153, 154

SILVA, Ruan Fernandes da, 105

SILVA, Semíramis Corsi, 121

SIMÕES, Vivian Carneiro Leão, 89, 133

SIMÕES, Carla Meneses (org.), 53

SOUZA, Aláya Dullius de, 37

SZLEZÁK, Thomas Alexander, 27

TAORMINA, Daniela P., (org.), 17

TAVARES, Andre Luís, 106

TEIXEIRA, Faustino (org.), 47

ULLMANN, Reinhold Aloysio, 3

VIANA, Isabela Vasconcellos (org.), 158

VIEIRA, Ivan, 14

ZINGANO, Marco (org.), 43

\section{ÍNDICE POR TRADUTORES}

BARACAT JUNIOR, José Carlos, 15, 16, 28, 101

GATTI, Icaro Francesconi, 69

LUPI, João, 22

LI, Willian, 54, 124

LOQUE, Flávio Fontenelle, 61

MARSOLA, Maurício Pagotto, 99

OLIVEIRA, Loraine, 15, 61, 157

OTTERMANN, Monika, 27

PEREIRA, Miguel Serras, 4

SANTOS, David G., 85

SILVA, Maria Aparecida de Oliveira, 120

SILVEIRA, Paulo Henrique Fernandes, 1

SOUZA, Aláya Dullius de, 10

VELOSA, Filipa, 114 


\section{ÍNDICE POR AUTORES ANTIGOS}

AGOSTINHO DE HIPONA, 108

ARISTÓTELES, 2, 27

BOÉCIO, 24, 25, 51, 54, 64, 74, 87, 103, 115, 119, 122, 124, 129

DIONÍSIO, 110, 123

EUSÉBIO DE CESARÉIA, 15

FILOPONO DE ALEXANDRIA, 43

HIPÁTIA, HIPÁCIA, HYPATIA, 4, 26, 121, 128, 132, 155, 156

IRENEU DE LYON, 23

JÂMBLICO, 14, 18, 30, 36, 49, 68, 71, 72, 96, 97, 98, 126, 136, 160

JULIANO, 9, 13, 28, 62, 63, 104, 125

ORÁCULOS CALDEUS, 160

MÁRIO VITORINO, 89, 133

MESTRE ECKHART, 110

PLATÃO, 27, 49, 82, 109, 131, 144

PLOTINO, 1, 2, 3, 6, 8, 10, 12, 15, 16, 17, 18, 20, 21, 22, 23, 27, 32, 33, 37, 39, 40, 44, 46, 47, 48, 49, $50,53,55,56,57,58,59,60,61,67,70,73,75,76,77,79,81,82,84,85,86,90,91,92,99,100$, $101,102,105,107,108,111,112,113,114,116,117,118,120,127,130,131,134,135,140$, $143,144,147,148,149,150,152,153,154,157,158,159$

PORFÍRIO, 18, 29, 42, 110

PROCLO, 5, 7, 10, 34, 69, 88, 109, 123, 137, 138, 139, 141, 142, 144, 145, 146

SINÉSIO, 45, 66, 93, 94, 95

TOMÁS DE AQUINO, 106

\section{ÍNDICE POR ASSUNTOS}

Alma, 20, 58, 75, 84, 105, 111, 114, 118, 159

Amor, 75, 120

Arte, 51, 62, 83, 133, 143

Ascensão, 39, 57, 79, 90, 91, 111, 159

Beleza, 51

Belo, 11, 41, 53, 158

Conhecimento, 44, 105

Contemplação, 8, 136

Contemporaneidade, 48, 52, 65, 87

Cosmo v. Cosmologia

Cosmologia, 21, 22, 82, 113, 143, 149

Cristianismo, 78

Deus, 32, 38, 116

Dionísio, 110, 123

Estética, 11, 40, 51, 79

Ética, 70, 85, 130 
A PLOTINO E AO NEOPLATONISMO DA ANTIGUIDADE TARDIA

Felicidade, 30, 74, 103

Geometria, 5

Gnosticismo, 23

Homem, 12, 134

Humano v. Homem

Imagem, 46

Inteligível, 35, 46, 143

Inteligência, 110

Linguagem, 68, 73, 80, 81

Lógica, 43, 73

Metafísica, 24, 43, 70, 85, 99

Mística, 6, 8, 29, 33, 34, 38, 47, 68, 73, 80, 81, 117

Mito, 10, 35, 77, 94, 100

Moral, 113

Mundo, 20, 43, 63, 104, 145

Número, 51

Paganismo, 31

Processão, 136

Razão, 53

Saber v. Conhecimento

Ser, 87, 110, 122

Tempo, 2, 101, 102, 114

Teologia, 7

Um v. Uno

Uno, 1, 12, 79, 81, 107, 116

Universais, 42

Unidade, 7, 87, 105 